\title{
Issues in dietary intake assessment of children and adolescents
}

\author{
M. B. E. Livingstone, P. J. Robson and J. M. W. Wallace \\ Northern Ireland Centre for Food and Health, University of Ulster, Coleraine, Co. Londonderry, BT52 1SA, UK
}

\begin{abstract}
Studies of food habits and dietary intakes face a number of unique respondent and observer considerations at different stages from early childhood to late adolescence. Despite this, intakes have often been reported as if valid, and the interpretation of links between intake and health has been based, often erroneously, on the assumption of validity. However, validation studies of energy intake data have led to the widespread recognition that much of the dietary data on children and adolescents is prone to reporting error, mostly through under-reporting. Reporting error is influenced by body weight status and does not occur systematically across different age groups or different dietary survey techniques. It appears that the available methods for assessing the dietary intakes of children are, at best, able to provide unbiased estimates of energy intake only at the group level, while the food intake data of most adolescents are particularly prone to reporting error at both the group and the individual level. Moreover, evidence for the existence of subject-specific responding in dietary assessments challenges the assumption that repeated measurements of dietary intake will eventually obtain valid data. Only limited progress has been made in understanding the variables associated with misreporting in these age groups, the associated biases in estimating nutrient intakes and the most appropriate way to interpret unrepresentative dietary data. Until these issues are better understood, researchers should exercise considerable caution when evaluating all such data.
\end{abstract}

Children: Adolescents: Dietary assessment

\section{Introduction}

The accurate assessment of food intakes in children and adolescents is an essential prerequisite for monitoring the nutritional status of these age groups, as well as for conducting epidemiological and clinical research on the links between diet and health. The measurement of energy and nutrient intakes in children and adolescents is particularly challenging because of the many unique respondent and observer considerations which surface at different ages from early childhood to late adolescence (Livingstone \& Robson, 2000). Consequently, their food intakes are prone to reporting error, but, until recently, the magnitude and direction of the bias have been impossible to gauge. Nevertheless, dietary intakes have often been reported as if valid, and the interpretation of links between intake and health was based, often erroneously, on this assumption.

In the present paper, the main measurement issues that may impact on reporting accuracy when assessing the dietary intakes of children and adolescents are evaluated. In addition, validation studies using doubly labelled water as a biomarker of energy intake (EI), variables associated with misreporting, and issues related to the identification of misreporters and data interpretation are reviewed.

\section{Cognitive aspects of dietary reporting}

Parental dietary recall

Until children reach the developmental stage when they are aware of their food intake and can begin to conceptualize time (at approximately 7-8 years of age), the onus of dietary reporting falls on parents. Parents may reliably report their children's food intake in the home setting (Klesges et al. 1987, 1988; Eck et al. 1989; Basch et al. 1990; Baranowski et al. 1991) but often do not know what their children consume outside the home (Baranowski et al. 1991). Other care-givers such as child minders may be involved in the reporting process, but it is likely that they will approach the task with varying levels of motivation and interest.

It is generally thought that, before the age of 12 years, children's recall skills, ability to estimate and indicate portion size, and knowledge of foods are limited, which, in turn, constrains their ability to self-report their food intake without parental assistance. Nevertheless, from the age of about 7-8 years there is a fairly rapid increase in the ability of children to participate in unassisted recall, but only for food eaten in the immediate past and for no longer than the previous $24 \mathrm{~h}$. Even then, it is likely that children may just be old enough to cope with remembering weekday food intake, but less so with the more irregular eating pattern associated with weekend days (Haraldsdóttir \& Hermansen, 1995). These findings, which have been endorsed by others, suggest that by the age of $8-10$ years children can reliably report their food intake, often as reliably as their parents (Emmons \& Hayes, 1973; Van Horn et al. 1990; Achterberg et al. 1991; Lytle et al. 1993; Sobo et al. 2000). Where the input of parents 
is likely to be important is in providing details about the types and quantities of food consumed, because of children's more limited food vocabularies (Sobo et al. 2000). Therefore, at a group level, repeated $24 \mathrm{~h}$ recalls in this age group may be a feasible alternative to a diet history interview with parents (Haraldsdóttir \& Hermansen, 1995). However, whether children younger than 10 years could give valid responses to a food frequency questionnaire (FFQ) covering periods greater than $1 \mathrm{~d}$ is much more debatable because of their inability to conceptualize frequency, averaging, etc. (Baranowski et al. 1986; Domel et al. 1994a).

In conclusion, the assumption that parents are good surrogate reporters of their children's food intake does not always hold in practice and this must be regarded as a limiting factor in studies using recall methodology for assessing the food intakes of young children.

\section{Portion size estimation}

The quantification of the amount of food eaten, other than by direct weighing, includes a largely unknown component of error (Cypel et al. 1997). Early studies suggested that young children cannot estimate portion size accurately, even when prompted with visual aids (Huenemann \& Turner, 1942; Meredith et al. 1951). However, older children and adolescents also experience difficulty in reporting portion size, which suggests that the ability of children to estimate portion sizes is not age-dependent.

Overall, in the majority of studies that have used quantification tools such as household measures and graduated food models, scant attention has been paid to the efficacy, or otherwise, of such aids (Moore et al. 1967; Emmons \& Hayes, 1973; Frank et al. 1977; Carter et al. 1981; Jenner et al. 1989; Lytle et al. 1993). Estimating the amount of food consumed is a complex cognitive task (Friedenreich et al. 1992) which many children, because of their developmental stage, have probably not mastered (Baranowski \& Domel, 1994; Matheson et al. 2002). Indeed, many adults, even those with advanced nutritional knowledge, have considerable difficulty in visually estimating quantity (Chambers et al. 2000). It requires that children can recognize and describe food quantities in terms of proportions or whole units and that they have an adequately developed concept of time to express food intake in terms of frequency and averages. It also assumes that the child can think abstractly about food while viewing generic food models of different volumes and dimensions, or other tools such as food photographs. It is highly unlikely, therefore, that estimation of portion size is compatible with the perceptual and conceptual capacities of children who have not reached the stage of abstract reasoning (approximately 10-11 years). The problem is further compounded by the fact that food frequencies and portion sizes consumed by children are not constant over time and, in any case, it is most unlikely that they pay attention to frequencies and portion sizes when they are eating. It is therefore not surprising that the tasks involved in food quantification will be beyond the intellectual capacities of many children.

Training in portion size estimation is known to improve the accuracy of dietary self-reporting in adults, but there are few comparable data in children. In the most rigorous assessment to date, Weber et al. (1999) investigated the effect of a 45 min training exercise in portion size estimation on improving the accuracy of estimated food portions in children aged $9-10$ years. The training did result in significant improvements in the ability to quantify foods, with the greatest improvements shown for solid foods estimated by dimensions and cups, and for liquids estimated by volume (cups), or by reading package labels. Amorphous foods were estimated least accurately both before and after training. Nevertheless, despite the considerable improvements in estimation capability, the error for several foods remained $>100 \%$ of the true quantity, indicating that more than one training session would be required to further improve reporting accuracy.

In conclusion, there is a clear need for novel methods for estimating portion sizes that are sensitive to the cognitive abilities of children. Until then, it must not be assumed that inclusion of any quantification tool will assist children to estimate portion sizes more accurately. It may merely confuse children at best, or exacerbate the problem at worst.

\section{How children remember}

One of the largest concerns about dietary surveys based on recall is their ultimate reliance on memory, which is subject to a variety of errors (Dwyer et al. 1987). However, while the importance of good memory is acknowledged, it is unlikely that many researchers fully appreciate the cognitive processes involved during dietary recall. These processes involve understanding what information is being asked for, and searching for and evaluating the retrieved information before providing a response. Errors can arise at any of these stages, either because the respondent is unable to complete the cognitive tasks involved or because they have been prevented from doing so by inappropriate cues on the part of the observer. It has been suggested that what is eaten is rarely encoded into longterm memory, but perhaps is stored in a somewhat 'generic' memory (Bradburn et al. 1987; Nelson, 1993). Not surprisingly, recall errors increase as a function of time and up to $30 \%$ of food memory may be lost from the previous day (Fries et al. 1995).

The limited research on children's recall of food intake shows that it is prone to considerable error. These errors include both under-reporting (missing foods), over-reporting (phantom foods; Meredith et al. 1951; Samuelson, 1970; Emmons \& Hayes, 1973; Baranowski et al. 1986; Simons-Morton et al. 1990; Crawford et al. 1994; Domel et al. 1994b; Domel, 1997), and incorrect identification of foods (Meredith et al. 1951; Samuelson, 1970; Emmons \& Hayes, 1973). Other factors that may impact on recall accuracy include: information overload, whereby there is an increased tendency to under-report as the number of foods eaten at a meal or overall eating frequency increases (Meredith et al. 1951; Baranowski et al. 1986); prevailing distractions (Baranowski et al. 1986); and salience of the food items in the diet, such that common foods or main course items are more easily recalled than less common foods or ancillary items (Emmons \& Hayes, 1973; Baxter et al. 1999). 
Unfortunately, most studies have been mainly concerned with short-term recall, often within $2 \mathrm{~h}$ of eating. Consequently the observed errors may have less to do with memory decay than they are to inattention. Errors in dietary recall attributable to memory decay are probably those that involve failure to report a percentage of foods eaten as a function of time and/or the developmental stage of the child. Clearly, there are limits to what children can remember, but to date little is known about the cognitive constraints on their ability to retain and retrieve dietary information.

Baranowski \& Domel (1994) have proposed a model of how children remember and process information in which the cognitive processes involved in the recall of dietary information can be categorized as attention, perception, organization, retention, retrieval and response formulation. Further work with this model has demonstrated that children employ a number of retrieval strategies during selfreport of their dietary intake: visual imagery (appearance of the food); usual practice (familiarity with eating the food); behaviour chaining (association with preferred food or favourite activity during a meal or day); and preference (favourite food). Non-directive prompts and cues have been shown to be vital to gain maximum recall (Baxter et al. 1997; Warren et al. 2003). While the insights gained from cognitive psychology about how food-related information is stored, retrieved and recalled by children are encouraging, further research is clearly needed to address many unresolved issues such as the impact of time lapse and less experimentally controlled conditions on retention and retrieval responses.

\section{Variability in nutrient intake}

In epidemiological investigations of diet-health relationships in children and adolescents, accurate estimates of the intake of specific nutrients is vital to correctly rank or classify subjects in the distribution of intakes. The number of days of records or recalls required to rank individuals depends on within-subject:between-subject variance (variance ratio) in nutrient intake: the larger the ratio, the more days of recording are required to rank individuals correctly. The few studies that have examined this issue in children and adolescents have clearly demonstrated that the variance ratios for children's nutrient intakes are much greater than are those for adults (Farris et al. 1985a,b; Nelson et al. 1989; Miller et al. 1991).

In younger children $(<4$ years old $)$, the variance ratios are relatively low; therefore, $7 \mathrm{~d}$ of records are probably adequate for ranking subjects for energy and most nutrients. This has been substantiated by Birch et al. (1991), who examined the intra-individual variability in EI over $6 \mathrm{~d}$ in children aged $2-5$ years. In contrast to the mean $\mathrm{CV}$ of $33.6 \%$ for each child's EI at individual meals, the mean CV for each child's total daily EI was only $10.4 \%$. Thus within-subject daily EI is relatively constant because children adjust their EI at successive meals.

In contrast, the variance ratios for older children and adolescents (5-17 years) are, in general, approximately twice that observed in adults. Consistently higher values are observed in females, implying that males will be ranked more accurately for most nutrients for a given study period. As might be expected, the variability in intake is lowest for the nutrients that are eaten regularly in the diet and highest for those nutrients that are eaten in large amounts only occasionally. Vitamin intakes, e.g. carotene, retinol and vitamin $\mathrm{E}$, are the most variable, often requiring $>20 \mathrm{~d}$ of records to capture habitual intake, particularly in girls. Higher variance ratios for nutrient intakes in these groups have a number of important implications for the design and interpretation of dietary surveys.

First, the finding that prolonged recording may be required to characterize the intakes of many nutrients has major implications for the choice of survey instrument and the design of surveys. Clearly, ranking of children and adolescents based on only $7 \mathrm{~d}$ of records or recalls will be grossly inaccurate. On one hand, this issue calls into question the feasibility of using intrusive and burdensome instruments such as weighed or estimated dietary records (whose validity has, in any case, been questioned in older children and adolescents) or recalls, even if splitting the required recording period into discrete time periods is entertained. On the other hand, the application of FFQ or diet histories must be carefully evaluated, given the numerous problems in their application, such as retrieval of dietary information from memory, conceptualization skills and portion size estimation.

Second, these high variance ratios have been based, at least until recently, on the assumption that the dietary data represent valid measures of habitual food intake. However, the recognition that self-reported dietary intakes, particularly in adolescents, are likely to be biased, mainly in the direction of under-reporting (Bandini et al. 1990, 1997; Livingstone et al. 1992; Bratteby et al. 1998), has implications for the way in which such surveys are interpreted. Since under- and over-reported intakes will extend the range of reported intakes, the ranking of these subjects into the extremes of the distribution may be invalid and result in biased conclusions. There is evidence that the range of 'habitual' energy expenditure is narrower than the range of reported EI. The total between-subject variation in 574 measurements of energy expenditure (EE) by the doubly labelled water method (including 163 children and adolescents) from seventy-four studies was $15.4 \%$ (Black et al. 1996). However, in studies with repeated measurements of $\mathrm{EE}$ by the doubly labelled water method, the true between-subject variation may be approximately $12 \%$ (Black \& Cole, 2000). If this value represents the range of 'habitual' energy expenditure, then it must also represent the range of 'habitual' EI. However, dietary surveys on children and adolescents typically report a total between-subject variation in EI of approximately $20 \%$, or even higher. This finding suggests that over- and under-reporting substantially extend the range of reported intakes beyond 'habitual' intakes. The effect of this could be to give a false impression of the ability to rank subjects, simply because the extreme values of a population distribution may reflect over- and under-reporting rather than true high or low intakes. The extent to which the observed high variability in the nutrient intake 
Table 1. Comparisons of reported energy intake (EI) with energy expenditure (EE) measured by the doubly labelled water method in children and adolescents aged $1-18$ years

\begin{tabular}{|c|c|c|c|c|c|c|c|}
\hline \multirow[b]{2}{*}{ Subjects } & \multirow[b]{2}{*}{$n$} & \multirow[b]{2}{*}{ Sex } & \multirow{2}{*}{$\begin{array}{c}\text { Age } \\
\text { (years) }\end{array}$} & \multirow[b]{2}{*}{ Diet method } & \multicolumn{2}{|c|}{ El:EE } & \multirow[b]{2}{*}{ Reference } \\
\hline & & & & & Mean & SD & \\
\hline \multicolumn{8}{|l|}{ Young children } \\
\hline England & 81 & MF & $1.5-4.5$ & $4 d$ WR & 0.97 & - & Davies et al. (1994) \\
\hline Scotland & 41 & MF & $3-4$ & $3 \times M P 24 h R$ & $1 \cdot 12$ & - & Reilly et al. (2001) \\
\hline N. Ireland & 20 & MF & $3-5$ & $\mathrm{DH}$ & $1 \cdot 12$ & 0.19 & Livingstone et al. (1992) \\
\hline USA & 45 & MF & $4-7$ & FFQ & 1.59 & - & Kaskoun et al. (1994) \\
\hline USA & 24 & MF & $4-7$ & $3 \times M P 24 h R$ & 0.97 & - & Johnson et al. (1996) \\
\hline England & 8 & $\mathrm{M}$ & $4-6$ & $7 d$ WR & 0.82 & 0.21 & Smithers et al. (1998) \\
\hline England & 6 & $\mathrm{~F}$ & $4-6$ & $7 d$ WR & 0.79 & 0.22 & Smithers et al. (1998) \\
\hline USA & 146 & MF & $4-11$ & $3 \times M P 24 h R$ & $1 \cdot 10$ & 0.31 & Fisher et al. (2000) \\
\hline N. Ireland - low risk of obesity & 50 & MF & 6 & $7 d$ WR & 0.98 & 0.17 & McGloin et al. (2002) \\
\hline N. Ireland - high risk of obesity & 50 & MF & 6 & $7 d$ WR & 0.95 & 0.19 & McGloin et al. (2002) \\
\hline N. Ireland - obese & 14 & MF & 6 & $7 d$ WR & 0.86 & 0.16 & McGloin et al. (2002) \\
\hline \multicolumn{8}{|l|}{ Pre-puberty } \\
\hline N. Ireland & 11 & M & $7-9$ & $\mathrm{DH}$ & $1 \cdot 13$ & 0.23 & Livingstone et al. (1992) \\
\hline N. Ireland & 12 & $\mathrm{~F}$ & $7-9$ & $\mathrm{DH}$ & 1.07 & 0.18 & Livingstone et al. (1992) \\
\hline N. Ireland & 11 & M & $7-9$ & $7 \mathrm{~d} W R$ & $1 \cdot 18$ & 0.22 & Livingstone et al. (1992) \\
\hline N. Ireland & 12 & $\mathrm{~F}$ & $7-9$ & $7 d$ WR & 0.96 & 0.16 & Livingstone et al. (1992) \\
\hline England & 13 & M & $7-10$ & $7 d$ WR & 0.93 & 0.13 & Smithers et al. (1998) \\
\hline England & 13 & $\mathrm{~F}$ & $7-10$ & $7 d$ WR & 0.80 & 0.14 & Smithers et al. (1998) \\
\hline USA & 50 & MF & $8-16$ & FFQ & 1.02 & - & Perks et al. (2000) \\
\hline USA - African-American & 45 & MF & 8 & $2 \times M P 24 h R$ & $1 \cdot 14$ & - & Ku et al. (1998) \\
\hline USA - Caucasian & 21 & MF & 8 & $2 \times M P 24 h R$ & 1.24 & - & Ku et al. (1998) \\
\hline USA & 14 & $\mathrm{~F}$ & 8 & $7 d \mathrm{ER}$ & 0.97 & - & Bandini et al. (1997) \\
\hline USA & 40 & $\mathrm{~F}$ & 9 & $7 \mathrm{~d} E R$ & 0.65 & - & Bandini et al. (1997) \\
\hline USA & 33 & $\mathrm{~F}$ & 10 & $7 \mathrm{dER}$ & 0.84 & - & Bandini et al. (1997) \\
\hline USA & 19 & $\mathrm{~F}$ & 11 & $7 \mathrm{~d} \mathrm{ER}$ & 0.81 & - & Bandini et al. (1997) \\
\hline Scotland & 20 & MF & $10 \cdot 7 \pm 3$ & $3 d E R$ & 0.84 & - & Reilly et al. (1998) \\
\hline USA - African-American & 27 & $\mathrm{~F}$ & $9-12$ & $8 \mathrm{~d} \mathrm{ER}$ & 0.74 & - & Champagne et al. (1998) \\
\hline USA - African-American & 29 & M & $9-12$ & $8 \mathrm{~d} \mathrm{ER}$ & 0.72 & - & Champagne et al. (1998) \\
\hline USA - Caucasian & 31 & $\mathrm{~F}$ & $9-12$ & $8 \mathrm{~d} E R$ & 0.76 & - & Champagne et al. (1998) \\
\hline USA - Caucasian & 31 & $M$ & $9-12$ & $8 \mathrm{~d} \mathrm{ER}$ & 0.83 & - & Champagne et al. (1998) \\
\hline USA - African-American & 5 & $\mathrm{~F}$ & 11 & $8 \mathrm{dER}$ & 0.67 & - & Champagne et al. (1996) \\
\hline USA - African-American & 6 & M & 11 & $8 \mathrm{dER}$ & 0.60 & - & Champagne et al. (1996) \\
\hline USA - Caucasian & 6 & $\mathrm{~F}$ & 11 & $8 \mathrm{~d} \mathrm{ER}$ & 0.88 & - & Champagne et al. (1996) \\
\hline USA - Caucasian & 6 & M & 11 & $8 \mathrm{~d} E R$ & 0.85 & - & Champagne et al. (1996) \\
\hline N. Ireland & 6 & M & 12 & $\mathrm{DH}$ & 1.07 & 0.19 & Livingstone et al. (1992) \\
\hline N. Ireland & 6 & $\mathrm{~F}$ & 12 & $\mathrm{DH}$ & 1.20 & 0.14 & Livingstone et al. (1992) \\
\hline N. Ireland & 6 & M & 12 & $7 d$ WR & 0.92 & 0.10 & Livingstone et al. (1992) \\
\hline N. Ireland & 6 & $\mathrm{~F}$ & 12 & $7 \mathrm{~d}$ WR & 0.85 & 0.12 & Livingstone et al. (1992) \\
\hline \multicolumn{8}{|l|}{ Adolescents } \\
\hline USA - African-American & 41 & $\mathrm{~F}$ & 13 & $3 d \mathrm{ER}$ & 0.72 & - & Wong et al. (1999) \\
\hline USA - Caucasian & 40 & $\mathrm{~F}$ & 13 & $3 d E R$ & 0.64 & - & Wong et al. (1999) \\
\hline England & 12 & M & $11-14$ & $7 \mathrm{~d} W R$ & 0.71 & 0.24 & Smithers et al. (1998) \\
\hline England & 9 & $\mathrm{~F}$ & $11-14$ & $7 d$ WR & 0.76 & 0.13 & Smithers et al. (1998) \\
\hline USA - lean & 28 & MF & $12-18$ & $14 \mathrm{~d} E R$ & 0.81 & 0.19 & Bandini et al. (1990) \\
\hline USA - obese & 27 & MF & $12-18$ & $14 \mathrm{~d}$ ER & 0.59 & 0.24 & Bandini et al. (1990) \\
\hline USA & 14 & $\mathrm{~F}$ & $12-16$ & $7 d \mathrm{ER}$ & 0.78 & 0.17 & Bandini et al. (1997) \\
\hline N. Ireland & 11 & M & $15-18$ & $\mathrm{DH}$ & 1.03 & 0.21 & Livingstone et al. (1992) \\
\hline N. Ireland & 11 & $\mathrm{~F}$ & $15-18$ & $\mathrm{DH}$ & 0.96 & 0.21 & Livingstone et al. (1992) \\
\hline N. Ireland & 11 & M & $15-18$ & $7 d$ WR & 0.77 & 0.23 & Livingstone et al. (1992) \\
\hline N. Ireland & 11 & $\mathrm{~F}$ & $15-18$ & $7 \mathrm{~d} W R$ & 0.72 & 0.20 & Livingstone et al. (1992) \\
\hline Sweden & 25 & M & 15 & $7 d$ WR & 0.82 & 0.18 & Bratteby et al. (1998) \\
\hline Sweden & 25 & $\mathrm{~F}$ & 15 & $7 \mathrm{~d} W R$ & 0.78 & 0.16 & Bratteby et al. (1998) \\
\hline England & 5 & M & $15-17$ & $7 d$ WR & 0.97 & 0.09 & Smithers et al. (1998) \\
\hline England & 10 & $\mathrm{~F}$ & $15-17$ & $7 \mathrm{~d} W R$ & 0.63 & 0.18 & Smithers et al. (1998) \\
\hline USA - controls & 10 & M & $15-17$ & $3 \mathrm{~d} E R$ & 1.04 & - & Ambler et al. (1998) \\
\hline USA - exercising subjects & 10 & M & $15-17$ & $3 \mathrm{~d} E R$ & 0.89 & - & Ambler et al. (1998) \\
\hline USA - controls & 6 & $\mathrm{~F}$ & $15-17$ & $3 d E R$ & 1.01 & - & Ambler et al. (1998) \\
\hline USA - exercising subjects & 6 & $\mathrm{~F}$ & $15-17$ & $3 \mathrm{~d} \mathrm{ER}$ & 0.79 & - & Ambler et al. (1998) \\
\hline
\end{tabular}

M, male; F, female; WR, weighed record; MP24hR, multiple-pass $24 \mathrm{~h}$ recall; $\mathrm{DH}$, diet history; FFQ, food frequency questionnaire; ER, record in household measures/estimated weights. 
of children and adolescents can be attributed to bias in dietary reporting remains to be established.

\section{Tracking of nutrient intake}

Tracking has been defined as the maintenance of relative position in rank over time (Kelder et al. 1994). Given that physiological processes that lead to diet-related diseases in adulthood have their antecedents in childhood diet, a high degree of stability over time in nutrient intake implies that the primary prevention of diet-related chronic diseases should be initiated through interventions that are directed at children from the outset.

The data to support the contention that food and nutrient intake patterns in adulthood are established during childhood are not convincing. Moderate to good tracking of some, but not all, nutrients has been observed in younger children (Stein et al. 1991; Singer et al. 1995). However, this finding is perhaps not surprising, since food intakes were likely to have been supervised, controlled and reported mostly by parents and/or care-givers. It is also conceivable that the apparent stability in nutrient intakes may simply be due to the close proximity of the measurements.

Unfortunately, there are relatively few rigorously conducted longitudinal studies of sufficient duration that would permit an informed evaluation of the phenomenon of tracking. Boulton et al. (1995) assessed the tracking of dietary energy, fat and $\mathrm{Ca}$ intakes in an Australian cohort from the age of 1 to 15 years. The $\mathrm{Ca}$ intakes of the boys remained relatively consistent over time, and children who were 'big eaters' at a young age remained so. However, those children who had reported lower EI at younger ages became more evenly spread out across the distribution of intakes over time. On the other hand, when $\mathrm{Ca}$ intakes were monitored in Dutch males and females (The Amsterdam Growth and Health Longitudinal Study) over a 15year period (from age 13 to 27 years), the tracking was not sufficiently strong to identify subjects who were likely to have inadequate $\mathrm{Ca}$ intakes in adulthood (Welten et al. 1997). Tracking coefficients obtained in the same cohort for energy and the macronutrients were also slight to fair, indicative of poor maintenance in rank over time (Twisk et al. 1997). Over a 20-year period (from age 13 to 33 years), the tracking data for the same Dutch cohort have reinforced the earlier observations, leading the authors to conclude that food and nutrient intakes during adolescence are poor predictors of adult food and nutrient consumption patterns (Post et al. 2001). Even during adolescence, data from the Northern Ireland Young Hearts Project have demonstrated that between the ages of 12 and 15 years, nutrient intake is unstable over time (Robson et al. 2000).

Is it reasonable to expect that nutrient intakes during childhood/adolescence would strongly predict nutrient intake patterns in adulthood? In the first place, the assessment of tracking is fraught with methodological constraints. Bias in self-reports of food intake is pervasive and very difficult to quantify (Livingstone \& Black, 2003). Furthermore, repeat testing is likely to compound the response bias. Changes in nutrient databases may intro- duce additional errors in the estimation of nutrient intakes. Finally, food intake patterns at any given age reflect a complex interaction of biological, psychological and sociological factors, and it is inconceivable that these patterns (and associated nutrient intakes) would remain stable from childhood to adulthood.

In conclusion, there is very little evidence that nutrient intake patterns track over long periods of time, and the studies that have been undertaken provide few clues as to the most appropriate stages during childhood and adolescence for targeting nutrition education interventions.

\section{Validation of dietary intakes}

\section{Validation studies}

A valid (or accurate) dietary report is one that measures the true intake during the period of study (Livingstone \& Black, 2003), but, until the advent of biomarkers, independent and objective validation of dietary intakes was not possible. Despite this, most studies of dietary intakes in children and adolescents were reported as if valid, and the interpretation of links between intake and health was based, often erroneously, on the assumption of validity. However, since 1990, validation studies using estimates of EE by the doubly labelled water method as a biomarker of EI have conclusively demonstrated that much of the data is prone to bias, mostly through under-reporting.

Use of doubly labelled water as a biomarker of EI is based on the assumption of energy balance: under conditions of weight stability, EI and $\mathrm{EE}$ are equivalent. During growth and development children are normally in positive energy balance, but after infancy, energy accretion is only about $1-2 \%$ of EI (Kuzawa, 1998). Table 1 summarizes EI:EE in validation studies of food intake in children and adolescents. Unfortunately, most of these studies were carried out on small numbers of highly selected subjects across various age groups and the majority of the studies employed either weighed or estimated diet records. Nevertheless, the totality of the data indicates that while misreporting of EI in these groups is highly probable, reporting accuracy varies as a function of age, weight status and the dietary survey method used.

\section{Effect of age on validity}

The overall trend for the magnitude of under-reporting to increase with increasing age has several possible explanations. In younger children, reporting is the responsibility of a parent or care-giver and there is likely to be less access to unsupervised in- and out-of-home eating. For 7- to 12year-olds where reporting accuracy is highly variable, the novelty and curiosity of assisting in or self-reporting of food intakes may help to sustain enthusiasm for, and compliance in, dietary monitoring. However, by adolescence, the additional demands on recording imposed by increased energy requirements, unstructured eating patterns, a significant degree of out-of-home eating, concerns with selfimage and rebellion against authority may all contribute, to a greater or lesser extent, to poor compliance in dietary reporting. 


\section{Effect of body weight on validity}

Consistent with previous studies in adults (Livingstone \& Black, 2003), one of the most robust findings in dietary studies of children and adolescents is the positive association between low-energy reporting and increased body fatness, particularly in adolescents (Bandini et al. 1990). In younger children, the relationship between reporting accuracy and weight status is not so clear-cut. In some studies (Champagne et al. 1998; Fisher et al. 2000; McGloin et al. 2002), but not in others (Johnson et al. 1996; Bandini et al. 1997; Reilly et al. 2001), body fatness was a predictor of under-reporting. Of note, Fisher et al. (2000) also observed that, relative to under-reporters and acceptable reporters, those who over-reported EI were lighter and had less body fat.

Overall, the magnitude of under-reporting in obese subjects is also age-related, since up to $40 \%$ of EI in obese adolescents may go unrecorded (Bandini et al. 1990) compared with $25 \%$ in 10-year-olds (Champagne et al. 1998) and $14 \%$ in 6-year-olds (McGloin et al. 2002). Even in normal-weight adolescents a positive association between underestimation of food intake and a tendency towards increased body fatness and overweight has been observed (Livingstone et al. 1992; Bratteby et al. 1998). Biased reporting may be due to one or more of the following factors: a wilful failure to record because it is time-consuming and inconvenient; a conscious/subconscious need for social approval; subconscious memory lapses across all or selected dietary items such as snacks; and conscious dieting resulting in accurate but nevertheless unrepresentative food intake data. In addition, given the exaggerated preoccupation with body weight and image that is pervasive in adolescents, particularly girls, it is conceivable that obese teenagers may feel even more stigmatized about their fatness than obese adults (Wardle \& Beales, 1986; Hill et al. 1994).

In younger children where parents are acting as surrogate respondents of children's food intake, reporting accuracy may be compromised by parental obesity status and/or by the extent to which parents perceive that such information is a reflection of their child's weight. Parental adiposity status has not been found to undermine the integrity of dietary intake data of lean children (Johnson et al. 1996; Bandini et al. 1997; McGloin et al. 2002), but a bias towards underestimation of food intakes of obese 6to 7-year-old children who have at least one obese parent has been observed (McGloin et al. 2002).

Although low-energy reporting is not inevitable in these groups, obesity, dieting and weight consciousness have nevertheless been identified as having the most robust associations with misreporting. Researchers need to be alert, therefore, to the real probability of misreporting in these groups, either by the subjects themselves and/or by obese or weight-conscious parents who report their children's food intake.

\section{Effects of the dietary survey technique}

It is well recognized that the imposition of a particular survey technique may induce method-specific behavioural alterations in actual and reported food intake. The nature and extent of these constraints are difficult to quantify and, thus, the true validity of different dietary survey methods is unknown.

Most of the validation studies carried out on children and adolescents have employed diet records, either weighed or estimated. These have been shown to provide unbiased records of EI in lean subjects up to 9 years old (Livingstone et al. 1992; Davies et al. 1994; Bandini et al. 1997; McGloin et al. 2002). However, the studies of older children, adolescents and young adults unanimously show that EI by this method is under-reported by approximately $20 \%$, with the greatest bias being observed in the older subjects (Livingstone et al. 1992; Bandini et al. 1997; Bratteby et al. 1998). Thus, while mean EI by weighed dietary record was underestimated by $14 \%$ $(P<0.01)$ in 12 -year-olds, in 15 - to 18 -year-olds the magnitude of underestimation had increased to $24 \%(P<0.01$; Livingstone et al. 1992). Using $14 \mathrm{~d}$ estimated dietary records, Bandini et al. (1990) also showed a remarkably similar degree of under-reporting, with the negative bias being particularly pronounced in obese subjects. It appears, therefore, that the magnitude of under-reporting by diet records is independent of the specific method used to quantify food intakes.

Only one study to date has validated the diet history technique concurrently with weighed dietary records in children and adolescents (Livingstone et al. 1992). The former method apparently overcomes the age-related reporting bias of weighed dietary records. However, while the diet history obtained good mean intakes, the data lacked precision at the individual level, with $35 \%$ of the results by diet history lying outside the $95 \% \mathrm{CI}$ that assume a valid measure of habitual intake.

There have been relatively few studies assessing the validity of $24 \mathrm{~h}$ recalls and FFQ, which makes it difficult to generalize about the results. With the exception of the study by Johnson et al. (1996), which demonstrated that the multiple-pass $24 \mathrm{~h}$ recall accurately reflected mean EI, the other studies employing this protocol demonstrated a positive bias in mean EI (Ku et al. 1998; Fisher et al. 2000; Reilly et al. 2001). In all of these studies, accuracy at the individual level was poor. It has been speculated that inappropriate tools used to estimate portion size might partly account for the bias in some studies (Reilly et al. 2001). Results using FFQ have been highly variable. On one hand, valid mean intakes but significant individual variability in reporting accuracy have been noted in a group of prepubertal children and adolescents (Perks et al. 2000). In contrast, the Willett FFQ resulted in a significant overestimation of EI $(53 \%)$ in 4- to 7-year-olds, probably due to the inappropriate portion sizes built into the design (Kaskoun et al. 1994).

In summary, there have been too few validation studies in paediatric groups to justify advocating one particular method over another.

\section{Subject-specific response in dietary reporting}

Dietary surveys usually report a range of EI that, at the extremes of the distribution, cannot represent habitual 
intake. It has been customary to assume that these extreme values were obtained by chance due to day-to-day variation in food intake, but that with repeat measurements the extreme values would balance out to provide a valid measure of mean intake. However, it is conceivable that a subject who has under-reported dietary intake on one occasion will also under-report on a second occasion, in which case the bias cannot be eliminated by repeated measurements. It has also been suggested that estimates of intake can be improved by administering two different dietary assessment instruments, an approach that recognizes that there are large errors in all techniques, but assumes that the sources of error are independent in different methods.

The latter assumption has not been borne out in children and adolescents. When EI was assessed simultaneously by weighed dietary record and diet history, and validated by the doubly labelled water method (Livingstone et al. 1992), there was clear evidence of a subject-specific response, such that subjects who under-reported by the weighed dietary record also did so by the diet history. The strongest influence on EI:EE was the dietary assessment method $(P<0.0001)$, with the weighed dietary record showing the greater bias to under-reporting. The second most important influence was the age of the subject $(P<0 \cdot 001)$. Compared with 7-, 9- and 12-year-olds, 15and 18-year-olds showed a marked bias to under-reporting and a stronger tendency for these individuals to give a similar response to both methods. The effect of gender was small and not significant, with males just as likely to under-report as females.

Subject-specific bias has important implications for the analysis of dietary surveys. Under- and over-reported intakes will simply extend the range of reported intakes and will distort the ranking of subjects, resulting in biased conclusions (Black \& Cole, 2001).

\section{The detection of misreporting}

It is now widely accepted that misreporting is a major problem in dietary surveys, not just in adults, but also in children. What children say they eat is clearly not what they eat. Consequently, their dietary data can no longer be accepted at face value, and all data should be subjected to critical examination for evidence of bias. Unfortunately, the cost and technical complexity of the doubly labelled water technique preclude its routine use for detecting bias in EI data. However, reported EI can also be evaluated against presumed energy requirements, expressed as physical activity levels (PAL; Goldberg et al. 1991; Black, $2000 a$ ). This procedure, known as the Goldberg cut-off technique, was devised to evaluate the overall bias towards under-reporting at the group level. Although its use has been extended to identify under-reporters at the individual level, the cut-off is limited by low sensitivity, as it identifies only about $50 \%$ of under-reporters and, furthermore, it can make no distinction between varying degrees of misreporting (Black, 2000b). In addition, a common misinterpretation of the Goldberg cut-off technique is that the cut-offs, which were originally designed for screening the EI data of adults, can also be applied to the evaluation of the EI data of children and adolescents.

The effect of substituting the Golberg et al. (1991) cutoff for adults (based on an assumed PAL of 1.55 for a sedentary life-style) for the appropriate age- and genderspecific cut-offs for children (also based on an assumed light activity PAL) have been illustrated by Kersting et al. (1998) using a data set of $6953 \mathrm{~d}$ weighed dietary records by German children and adolescents aged 1-18 years. Based on a blanket cut-off derived from a PAL of 1.55 , approximately $10 \%$ of the records were excluded as implausible. The extent of misreporting varied by age, being lowest in the 1- to 5-year-olds (approximately $2 \%$ ) and highest in the adolescent males $(11 \%)$ and females $(31 \%)$. Since the appropriate age- and sex- specific cutoffs for children and adolescents (Torun et al. 1996) are lower than the cut-off based on a sedentary PAL of 1.55 for adults (except in older adolescent males aged 14-18 years), the overall effect of applying the former cut-offs was to reduce the exclusion rate to $6.5 \%$ in the total group, and to $20 \%$ in the adolescent females. Thus, the use of cut-offs that were never designed to evaluate the EI of children and adolescents can distort a data set by 'overestimating' the extent of dietary misreporting in these age groups. While the principles of the Goldberg et al. (1991) cut-off technique still hold good when assessing the EI of children and adolescents, appropriate ageand sex-specific cut-offs should always be applied in these population groups.

One of the major limitations in using a single EI:BMR cut-off based on a sedentary PAL value is that it will uncover only the probable degree of overall bias in a study, provided that a PAL value appropriate to that population is used for comparison. However, under-reporting occurs at all levels of levels of energy expenditure (Black, 1997) and, to improve sensitivity, methods need to be applied which will account for different levels of physical activity. Questionnaires have their errors and raise the issue of choosing appropriate PAL values for differing levels of physical activity. If more objective methods of assessing EE such as heart-rate monitoring are used, then EE can be estimated in absolute terms and EI can be then be compared directly with EE, in which case the Goldberg cut-off technique becomes redundant. However, the validity of techniques such as heart-rate monitoring for estimating EE also needs to be ensured before they come into common use for validating EI data (Livingstone et al. 2003).

Although most attention to date has focused on the issue of under-reporting, the possibility of systematic over-reporting cannot be excluded. At present, however, identification of its presence and magnitude in the EI data of children and adolescents is virtually impossible. The existing doubly labelled water data in these groups (Black et al. 1996) provide only limited information on which to define an appropriate PAL suitable for calculating a cut-off for identifying over-reporters. Caution should also be applied if using the age- and sex-specific PAL values for heavy habitual physical activity (Torun et al. 1996) because these were defined arbitrarily, not derived experimentally. 


\section{Consequences of misreporting}

Validation of dietary intakes against EE will identify bias in the reporting of EI only, but provides no clues as to whether this reflects under-reporting of the diet as a whole or if there is bias in estimating nutrient intakes through altered food choices and/or selective misreporting of foods. In relation to the dietary intakes of adults, the under-reporting of food intake tends to be a selective rather than a general phenomenon (Livingstone \& Black, 2003). Thus, bias in reporting of total EI is associated with variable bias in reporting macro- and micronutrient intakes, foods and meal patterns. Unfortunately, to date, few of the validation studies of children's food intakes have examined the data for selective misreporting. Kersting et al. (1998) noted that adolescent under-reporters recorded fewer daily snacks and a lower sugar intake (percentage of EI) than those deemed to be non-under-reporters. It was speculated that this finding might be due to specific omissions of sweet and/or snack foods. In contrast, Fisher et al. (2000) found no differences in macronutrient reporting among 4to 11-year-old children who were identified as under-reporters, accurate reporters or over-reporters. These data provide few insights into either the nature or the implications of misreporting in paediatric groups. For example, under-reported food intakes could produce serious exaggeration of deficient intakes, while selective misreporting of foods would seriously hamper derivation of food-based dietary guidelines. Thus, until the nature and magnitude of misreporting can be characterized, all dietary data on children and adolescents need to be interpreted with considerable caution. In the mean time, the most appropriate action to take when evaluating nutrient intake data is to assume that the reported intakes are minimum true intakes, while accepting that for some nutrients an over-estimation will be made.

\section{Conclusion}

Studies of the food habits and dietary intakes of children and adolescents face a number unique problems which are more or less specific to these age groups and which are highly likely to bias the outcome measurements. The cross-validation of EI data using doubly labelled water estimates of $\mathrm{EE}$ has led to the widespread recognition that much of the dietary data on children and adolescents is prone to reporting error, mostly in the form of underreporting. Moreover, this reporting bias does not occur systematically across age groups or different dietary survey techniques. It appears that the available methods for assessing the dietary intakes of children and adolescents are, at best, able to provide unbiased estimates of EI only at the group level in the younger age groups. The food intake data of most adolescents are particularly prone to reporting error at both the group and the individual level. To date, only limited progress has been made in understanding the variables associated with misreporting in these age groups, the associated biases in estimating nutrient intakes and the most appropriate way to interpret unrepresentative dietary data. Until these issues are better understood, researchers should exercise considerable caution when evaluating all such data.

\section{Acknowledgements}

This work was supported by a grant from the Nutritional Needs of Children Task Force of the European branch of the International Life Sciences Institute (ILSI Europe). Industrial members of this task force are Barilla, Coca-Cola, Danone Vitapole, Friesland Coberco, Masterfoods, Nestlé and Numico. Further information about ILSI Europe can be obtained from $+32(0) 27710014$ or info@ilsieurope.be. The opinions expressed herein are those of the authors and do not necessarily represent the views of ILSI and ILSI Europe.

\section{References}

Achterberg C, Pugh MA, Collins S, Getty VM \& Shannon B (1991) Feasibility of telephone interviews to collect dietary recall information from children. J Can Diet Assoc 54, 226-228.

Ambler C, Eliakim A, Brasel JA, Lee W-NP, Burke G \& Cooper DM (1998) Fitness and the effect of exercise training on the dietary intake of healthy adolescents. Int J Obes Relat Metab Disord 22, 354-362.

Bandini LG, Schoeller DA, Cyr HN \& Dietz WH (1990) Validity of reported energy intake in obese and nonobese adolescents. Am J Clin Nutr 52, 421-425.

Bandini LG, Cyr H, Must A \& Dietz WH (1997) Validity of reported energy intake in preadolescent girls. Am J Clin Nutr 65, 1138S-1141S.

Baranowski T \& Domel SB (1994) A cognitive model of children's reporting of food intake. Am J Clin Nutr 59, Suppl., 212S-217S.

Baranowski T, Dworkin R, Henske JC, Clearman DR, Dunn JK, Nader PR \& Hooks PC (1986) The accuracy of children's selfreports of diet: Family Health Project. J Am Diet Assoc 86, 1381-1385.

Baranowski T, Sprague D, Baranowski JH \& Harrison JA (1991) Accuracy of maternal dietary recall for preschool children. J Am Diet Assoc 91, 669-674.

Basch CE, Shea S, Arliss R, Contento IR, Rips J, Gutin B, Irigoyen M \& Zybert P (1990) Validation of mothers' reports of dietary intake by four to seven year-old children. Am J Public Health 80, 1314-1317.

Baxter SD, Thompson WO, Davis HC \& Johnson MH (1997) 'How do you remember you ate...?': a Delphi technique study to identify retrieval categories from fourth-grade children. J Am Diet Assoc 97, 31-36.

Baxter SD, Thompson WO, Davis HC \& Litaker MS (1999) Children's dietary recalls: the salience of entree and liking for foods on accuracy and order of reporting. Nutrition 15, 848-853.

Black AE (1997) Under-reporting of energy intake at all levels of energy expenditure: evidence from doubly labelled water studies. Proc Nutr Soc 56, 121A.

Black AE (2000a) Critical evaluation of energy intake using the Goldberg cut-off for energy intake:basal metabolic rate. A practical guide to its calculation, use and limitations. Int $J$ Obes Relat Metab Disord 24, 1119-1130.

Black AE (2000b) The sensitivity and specificity of the Goldberg cut-off for EI:BMR for identifying diet reports of poor validity. Eur J Clin Nutr 54, 395-404.

Black AE \& Cole TJ (2000) Within- and between-subject variation in energy expenditure measured by the doubly-labelled water technique: implications for validating reported dietary energy intake. Eur J Clin Nutr 54, 386-394.

Black AE \& Cole TJ (2001) Biased over- or under-reporting is 
characteristic of individuals whether over time or by different assessment methods. J Am Diet Assoc 101, 70-80.

Black AE, Coward WA, Cole TJ \& Prentice AM (1996) Human energy expenditure in affluent societies: an analysis of 574 doubly-labelled water measurements. Eur J Clin Nutr 50, $72-92$.

Birch LL, Johnson SL, Andresen G, Peters JC \& Schulte MC (1991) The variability of young children's energy intake. $N$ Engl J Med 324, 232-235.

Boulton TJC, Margarey AM \& Cockington RA (1995) Tracking of serum lipids and dietary energy, fat and calcium intake from 1 to 15 years. Acta Paediatr 84, 1050-1055.

Bradburn NM, Rips LJ \& Shevell SK (1987) Answering autobiographical questions: the impact of memory and inference on surveys. Science 236, 157-161.

Bratteby L-E, Sandhagen B, Fan H, Enghardt H \& Samuelson G (1998) Total energy expenditure and physical activity as assessed by the doubly labeled water method in Swedish adolescents in whom energy intake was underestimated by 7-d diet records. Am J Clin Nutr 67, 905-911.

Carter RL, Sharbaugh CO \& Stapell CA (1981) Reliability and validity of the 24-hour recall. J Am Diet Assoc 79, 542-547.

Chambers E, Godwin SL \& Vecchio FA (2000) Cognitive strategies for reporting portion sizes using dietary recall procedures. J Am Diet Assoc 100, 891-897.

Champagne CM, DeLany JP, Harsha DW \& Bray GA (1996) Underreporting of energy intake in biracial children is verified by doubly labeled water. J Am Diet Assoc 96, 707-709.

Champagne CM, Baker NB, DeLany JP, Harsha DW \& Bray GA (1998) Assessment of energy intake underreporting by doubly labeled water and observations on reported nutrient intakes in children. J Am Diet Assoc 98, 426-433.

Crawford PB, Obarzanek E, Morrison J \& Sabry ZI (1994) Comparative advantage of 3-day food records over 24-hour recall and 5-day food frequency validated by observation of 9- and 10-year-old girls. J Am Diet Assoc 94, 626-630.

Cypel YS, Guenther PM \& Petot GJ (1997) Validity of portionsize measurement aids: a review. J Am Diet Assoc 97, 289-292.

Davies PSW, Coward WA, Gregory J, White A \& Mills A (1994) Total energy expenditure and energy intake in the preschool child: a comparison. Br J Nutr 72, 13-20.

Domel SB (1997) Self-reports of diet: how children remember what they have eaten. Am J Clin Nutr 65, Suppl., 1148 S-1152S.

Domel SB, Baranowski T, Davis H, Leonard SB, Riley P \& Baranowski J (1994a) Fruit and vegetable food frequencies by fourth and fifth grade students: validity and reliability. J Am Coll Nutr 13, 33-39.

Domel SB, Thompson WO, Baranowski T \& Smith AF (1994b) How children remember what they have eaten. J Am Diet Assoc 94, 1267-1272.

Dwyer JT, Krall EA \& Coleman KA (1987) The problem of memory in nutritional epidemiology research. J Am Diet Assoc 87, 1509-1512.

Eck LH, Klesges RC \& Hanson CL (1989) Recall of a child's intake from one meal: are parents accurate? J Am Diet Assoc 89, 784-789.

Emmons L \& Hayes M (1973) Accuracy of 24-hr recalls of young children. J Am Diet Assoc 62, 409-415.

Farris RP, Cresanta JL, Frank GC, Webber LS \& Berenson GS (1985a) Dietary studies of children from a biracial population: intakes of carbohydrate and fiber in 10- and 13-year-olds. $\mathrm{J} \mathrm{Am}$ Coll Nutr 4, 421-435.

Farris RP, Cresanta JL, Frank GC, Webber LS \& Berenson GS (1985b) Dietary studies of children from a biracial population: intakes of vitamins in 10- and 13-year-olds. J Am Coll Nutr 4, 539-552.

Fisher JO, Johnson RK, Lindquist C, Birch LL \& Goran MI (2000) Influence of body composition on the accuracy of reported energy intake in children. Obes Res 8, 597-603.

Frank GC, Berenson GS, Schilling PE \& Moore MC (1977) Adapting the 24-hr recall for epidemiologic studies of schoolchildren. J Am Diet Assoc 71, 26-31.

Friedenreich CM, Slimani N \& Riboli E (1992) Measurement of past diet: review of previous and proposed methods. Epidemiol Rev 14, 177-196.

Fries E, Green P \& Bowen DJ (1995) What did I eat yesterday? Determinants of accuracy in 24-hour food memories. Appl Cogn Psychol 9, 143-155.

Goldberg GR, Black AE, Jebb SA, Cole TJ, Murgatroyd PR, Coward WA \& Prentice AM (1991) Critical evaluation of energy intake data using fundamental principles of energy physiology: 1. Derivation of cut-off limits to identify underrecording. Eur J Clin Nutr 45, 569-581.

Haraldsdóttir J \& Hermansen B (1995) Repeated 24-h recalls with young schoolchildren. A feasible alternative to diet history from parents? Eur J Clin Nutr 49, 729-739.

Hill AJ, Draper E \& Stack J (1994) A weight on children's minds: body shape dissatisfactions at 9-years old. Int $J$ Obes Relat Metab Disord 18, 383-389.

Huenemann RL \& Turner D (1942) Methods of dietary investigation. J Am Diet Assoc 18, 562-568.

Jenner DA, Neylon K, Croft S, Beilin LJ \& Vandongen R (1989) A comparison of methods of dietary assessment in Australian children aged 11-12 years. Eur J Clin Nutr 43, $663-673$.

Johnson RK, Driscoll P \& Goran MI (1996) Comparison of multiple-pass 24-hour recall estimates of energy intake with total energy expenditure determined by the doubly labeled water in young children. $J$ Am Diet Assoc 96, $1140-1144$.

Kaskoun MC, Johnson RK \& Goran MI (1994) Comparison of energy intake by semiquantitative food-frequency questionnaire with total energy expenditure by the doubly labeled water method in young children. Am J Clin Nutr 60, 43-47.

Kelder SH, Perry CL, Klepp K-I \& Lytle LL (1994) Longitudinal tracking of adolescent smoking, physical activity and food choice behaviours. Am J Public Health 84, 1121-1126.

Kersting M, Sichert-Hellert W, Lausen B, Alexy U, Manz F \& Schöch G (1998) Energy intake of 1 to 18 year old German children and adolescents. Z Ernährungswiss 37, 47-55.

Klesges RC, Klesges LM, Brown G \& Frank GC (1987) Validation of the 24-hour recall in preschool children. J Am Diet Assoc 87, 1383-1385.

Klesges RC, Hanson CL, Eck LH \& Durff AC (1988) Accuracy of self-reports of food intake in obese and normal weight individuals: effects of parental obesity on reports of children's dietary intake. Am J Clin Nutr 48, 1252-1256.

Ku C-Y, Gower BA, Nagy TR \& Goran MI (1998) Relationships between dietary fat, body fat and serum lipid profile in prepubertal children. Obes Res 6, 400-407.

Kuzawa CW (1998) Adipose tissue in human infancy and childhood: an evolutionary perspective. Am J Phys Anthropol Suppl. 27, 177-209.

Livingstone MBE \& Black AE (2003) Markers of the validity of reported energy intake. J Nutr 133, Suppl., 895S-920S.

Livingstone MBE \& Robson PJ (2000) Measurement of dietary intake in children. Proc Nutr Soc 59, 279-293.

Livingstone MBE, Prentice AM, Coward WA, Strain JJ, Black AE, Davies PSW, Stewart CM, McKenna PG \& Whitehead RG (1992) Validation of estimates of energy intake by weighed 
dietary record and diet history in children and adolescents. Am J Clin Nutr 56, 29-35.

Livingstone MBE, Robson PJ, Black AE, Coward WA, Wallace JMW, McKinley MC, Strain JJ \& McKenna PG (2003) An evaluation of the sensitivity and specificity of energy expenditure measured by heart rate and the Goldberg cut-off for energy intake:basal metabolic rate for identifying mis-reporting of energy intake by adults and children: a retrospective analysis. Eur J Clin Nutr 57, 455-463.

Lytle LA, Nichaman MZ, Obarzanek E, Glovsky E, Montgomery D, Nicklas T, Zive M \& Feldman H (1993) Validation of 24-hour recalls assisted by food records in third-grade children. $J$ Am Diet Assoc 93, 1431-1436.

McGloin AF, Livingstone MBE, Greene LC, et al. (2002) Energy and fat intake in obese and lean children at varying risk of obesity. Int J Obes Relat Metab Disord 26, 200-207.

Matheson DM, Hanson KA, McDonald TE \& Robinson TN (2002) Validity of children's food portion estimates: a comparison of 2 measurement aids. Arch Pediatr Adolesc Med 156, 867-871.

Meredith A, Matthews A, Zickefoose M, Weagley E, Wayave M \& Brown EG (1951) How well do children recall what they have eaten? J Am Diet Assoc 27, 749-751.

Miller JZ, Kimes T, Hui S, Andon MB \& Johnston CC (1991) Nutrient intake variability in a pediatric population: implications for study design. J Nutr 121, 265-274.

Moore MC, Judlin BC \& Kennemur P (1967) Using graduated food models in taking dietary histories. J Am Diet Assoc 51, 447-450.

Nelson K (1993) The psychological and social origins of autobiographical memory. Psychol Sci 4, 7-14.

Nelson M, Black AE, Morris JA \& Cole TJ (1989) Between- and within-subject variation in nutrient intake from infancy to old age: estimating the number of days required to rank dietary intakes with desired precision. Am J Clin Nutr 50, 155-167.

Perks SM, Roemmich JN, Sandow-Pajewski M, Clark PA, Thomas E, Weltman A, Patrie J \& Rogol AD (2000) Alterations in growth and body composition during puberty. IV. Energy intake estimated by the Youth-Adolescent FoodFrequency Questionnaire: validation by the doubly labeled water method. Am J Clin Nutr 72, 1455-1460.

Post GB, de Vente W, Kemper HCG \& Twisk JWR (2001) Longitudinal trends in and tracking of energy and nutrient intake over 20 years in a Dutch cohort of men and women between 13 and 33 years of age: The Amsterdam Growth and Health Longitudinal Study. Br J Nutr 85, 375-385.

Reilly JJ, Ventham JC, Ralston JM, Donaldson M \& Gibson B (1998) Reduced energy expenditure in preobese children treated for acute lymphoblastic leukemia. Pediatr Res 44, 557-562.

Reilly JJ, Montgomery C, Jackson D, MacRitchie J \& Armstrong $\mathrm{J}$ (2001) Energy intake by multiple pass $24 \mathrm{~h}$ recall and total energy expenditure: a comparison in a representative sample of 3-4-year-olds. Br J Nutr 86, 601-605.

Robson PJ, Gallagher AM, Livingstone MBE, Cran GW, Strain JJ, Savage JM \& Boreham CAG (2000) Tracking of nutrient intakes in adolescence: the experiences of the Young Hearts Project, Northern Ireland. Br J Nutr 84, 541-548.

Samuelson G (1970) An epidemiological study of child health and nutrition in a northern Swedish county. Nutr Metab 12, $321-340$.

Simons-Morton BG, Baranowski T, Parcel GS, O’Hara NM \& Matteson RC (1990) Children's frequency of consumption of foods high in fat and sodium. Am J Prev Med 6, 218-227.

Singer MR, Moore LL, Garrahie EJ \& Ellison RC (1995) The tracking of nutrient intake in young children: the Framingham Children's Study. Am J Public Health 85, 1673-1677.

Smithers G, Gregory J, Coward WA, Wright A, Elsom R \& Wenlock R (1998) British National Diet and Nutrition Survey of young people aged $4-18$ years: feasibility study of the dietary assessment method. Eur J Clin Nutr 52, S76.

Sobo EJ, Rock CL, Neuhouser ML, Maciel TL \& NeumarkSztainer D (2000) Caretaker-child interaction during children's 24-hour dietary recalls: who contributes what to the recall report? J Am Diet Assoc 100, 428-433.

Stein AD, Shea S, Basch CE, Contento IR \& Zybert P (1991) Variability and tracking of nutrient intakes of preschool children based on multiple administrations of the 24-hour dietary recall. Am J Epidemiol 134, 1427-1437.

Torun B, Davies PSW, Livingstone MBE, Paolisso M, Sackett R \& Spurr GB (1996) Energy requirements and dietary energy recommendations for children and adolescents 1 to 18 years old. Eur J Clin Nutr 50, Suppl., S37-S81.

Twisk JWR, Kemper HCG, van Mechelen W \& Post GB (1997) Tracking of risk factors for coronary heart disease over a 14-year period: a comparison between lifestyle and biologic risk factors with data from the Amsterdam Growth and Health Study. Am J Epidemiol 145, 888-898.

Van Horn LV, Gernhofer N, Moag-Stahlberg A, Farris R, Hartmuller G, Lasser VI, Stumbo P, Craddick S \& Ballew C (1990) Dietary assessment in children using electronic methods: telephones and tape recorders. J Am Diet Assoc 90, 412-416.

Wardle J \& Beales S (1986) Restraint, body image and food attitudes in children from 12-18 years. Appetite 7, 209-217.

Warren JM, Henry CJK, Livingstone MBE, Lightowler HJ, Bradshaw SM \& Perwaiz S (2003) How well do children aged 5-7 years recall food eaten at school lunch? Public Health Nutr 6, 41-47.

Weber JL, Cunningham-Sabo L, Skipper B, Lytle L, Stevens J, Gittelsohn J, Anliker J, Heller K \& Pablo JL (1999) Portion-size estimation training in second- and third- grade American Indian children. Am J Clin Nutr 69, Suppl., 782S-787S.

Welten DC, Kemper HCG, Post GB, Van Staveren WA \& Twisk JWR (1997) Longitudinal development and tracking of calcium and dairy intake from teenager to adult. Eur J Clin Nutr 51, $612-618$.

Wong WW, Butte NF, Ellis KJ, Hergenroeder AC, Hill RB, Stuff JE \& O'Brian Smith E (1999) Pubertal African-American girls expend less energy at rest and during physical activity than Caucasian girls. J Clin Endocrinol Metab 84, 906-911. 